\title{
Co-existence of the double inferior vena cava with complex interiliac venous communication and aberrant common hepatic artery arising from superior mesenteric artery: a case report
}

\author{
V. Chentanez, N. Nateniyom, T. Huanmanop, S. Agthong \\ Department of Anatomy, Faculty of Medicine, King Chulalongkorn Memorial Hospital, Chulalongkorn University, \\ Bangkok, Thailand
}

[Received: 19 June 2017; Accepted: 31 July 2017]

Variations of the arterial and venous system of the abdomen and pelvis have important clinical significance in hepatobiliary surgery, abdominal laparoscopy, and radiological intervention. A case of double inferior vena cava (IVC) with complex interiliac communication and variation of the common hepatic artery (CHA) arising from superior mesenteric artery (SMA) in a 79-year-old male cadaver is presented. Both IVCs ascended on either side of the abdominal aorta. The left-sided IVC crossed anterior to the aorta at the level of the left renal vein. The union of both IVCS was at the level just above the right renal vein. The diameter of right-sided IVC, left-sided IVC and the common IVC were $16.73 \mathrm{~mm}, 21.57 \mathrm{~mm}$ and $28.75 \mathrm{~mm}$, respectively. In the pelvic cavity, the right common iliac vein was formed by a union of right external and internal iliac veins while the formation of left common iliac vein was from the external iliac vein and two internal iliac veins. An interiliac vein ran from right internal iliac vein to left common iliac vein with an additional communicating vein running from the middle of this interiliac vein to the right common iliac vein. Another co-existence variation in this case was the origin of the CHA arising from the SMA with a suprapancreatic retroportal course. Clinical importance of double IVC are observed in retroperitoneal surgery, whole organ transplantation or radical nephrectomy, surgical ligation of the IVC or the placement of an IVC filter for thromboembolic disease. The variation of CHA has an important clinical significance in liver transplantation, abdominal laparoscopy and radiological abdominal intervention. (Folia Morphol 2018; 77, 1: 151-155)

Key words: double inferior vena cava, common hepatic artery, interiliac vein, superior mesenteric artery

\section{INTRODUCTION}

Double inferior vena cava (IVC) or duplication of IVC was first discovered by Lucas in 1916 [12]. The embryogenesis of the IVC in man was described in detail by McClure and Butler in 1925 [16]. The IVC is developed from three pairs of primitive vein, the postcardinal, subcardinal and supracardinal veins during weeks 4-8 of gestation [27]. Abnormal development, regression and anastomosis of these three pairs of primitive veins will cause anomalies and variations of the IVC. Duplication of the IVC is the most common anomaly affecting the IVC with a prevalence of $2-3 \%$ [2]. It results from 
the persistence of the caudal portion of the left supracardinal vein [16]. Double IVC may associate with various anomalies including cloacal extrophy, unilateral renal agenesis and right retrocaval ureter, hemiazygos continuation of IVC, retroaortic right renal vein, situs inversus and congenital heart disease $[4,10,30,34]$. Although double IVC is usually asymptomatic and diagnosed incidentally on abdominal imaging, it is important to recognise. It can be confused with abdominal aortic aneurysm or lymph node enlargement [11]. Important clinical consequences of double IVC are observed in retroperitoneal surgery, whole organ transplantation or radical nephrectomy and surgical ligation of the IVC or the placement of an IVC filter for thromboembolic disease [34]. The interiliac vein was previously reported to be in association with double IVC [6]. The iliac venous structures are at risk of haemorrhage due to vascular injury from the anterior peritoneal approach in prosthetic lumbar disk replacement surgery [35].

Common hepatic artery (CHA) is usually a branch of the coeliac trunk. Variation of its origin from the superior mesenteric artery (SMA) has been reported in several articles. The prevalence ranged $0.5-6.6 \%[1,5,9,17,20$, $23,28,29,31,33,37]$. This variation has an important clinical significance in liver transplantation, abdominal laparoscopy and radiological abdominal intervention [19]. To the best of our knowledge, there is no previous report of the co-existence of double IVC and aberrant CHA arising from the SMA. We report here a case of double IVC with complex interiliac communication and aberrant $\mathrm{CHA}$ arising from the SMA.

\section{CASE REPORT}

During a routine anatomical dissection of the abdomen at the Department of Anatomy, Faculty of Medicine, Chulalongkorn University, a case of double IVC with variation of the $\mathrm{CHA}$ arising from superior mesenteric artery in a 79-year-old male cadaver was presented. The dissection revealed a double IVC. Both IVCs ascended on either side of the abdominal aorta. The left-sided IVC crossed anterior to the aorta at the level of the left renal vein. The union of both IVCs was at the level just above the right renal vein (Fig. 1). The diameter of right-sided IVC, left-sided IVC and the common IVC were $16.73 \mathrm{~mm}, 21.57$ $\mathrm{mm}$ and $28.75 \mathrm{~mm}$, respectively. The common IVC passed through the diaphragm and ended in the right atrium. There was no abnormality of the drainage of azygos and hemiazygos veins. The diameter of right and left renal veins were $12.17 \mathrm{~mm}$ and $11.02 \mathrm{~mm}$,

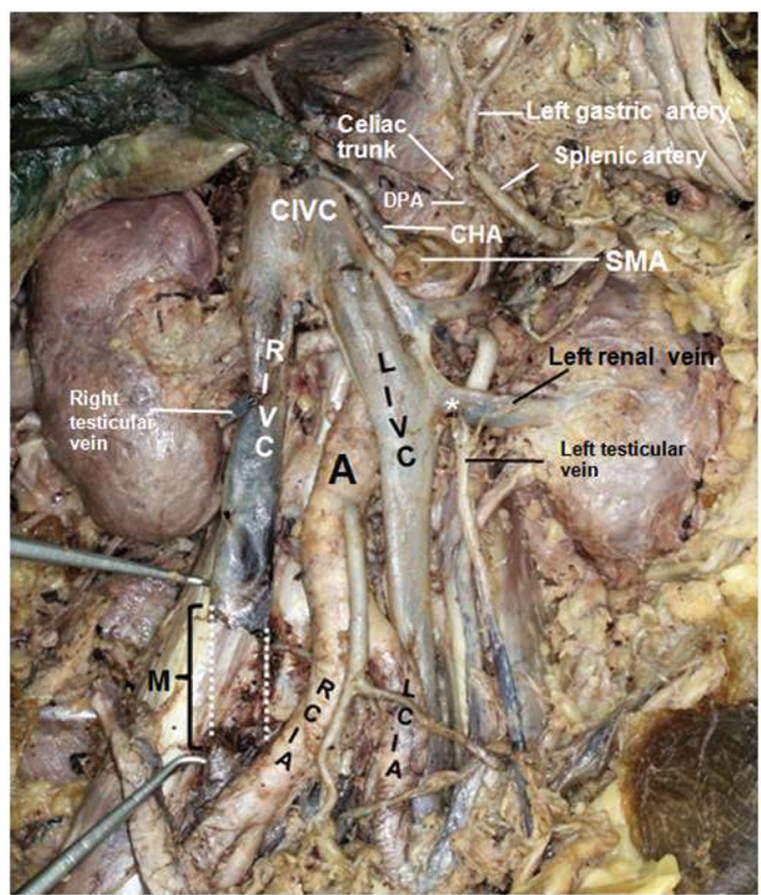

Figure 1. The retroperitoneal region showing the double inferior vena cava (IVC) and aberrant common hepatic artery (CHA) from the superior mesenteric artery (SMA); DPA — dorsal pancreatic artery; RIVC right-sided inferior vena cava; LIVC — left-sided inferior vena cava, the union of both IVCs (CIVC) and the missing part of RIVC (M). The right testicular vein drained into the right common iliac artery (RIVC). The left testicular vein drained into the left renal vein (white asterisk). The LIVC crossed the abdominal aorta (A); LCIA — left common iliac artery.

respectively. The right testicular vein drained directly into the right-sided IVC and the left testicular vein into the left renal vein (Fig. 1). In the pelvic cavity, the right-sided IVC or right common iliac vein was formed by a union of right external and internal iliac veins while the left common iliac vein was formed by the external iliac vein and two internal iliac veins. At the beginning of the right-sided IVC, a part of it was accidentally removed during student dissection (Fig. 2). A complex interiliac vein communication was observed (Fig. 2). The direction of interiliac vein ran from right internal iliac vein to left common iliac vein. Another communicating vein ran from the middle of this interiliac vein to the right common iliac vein. Moreover, an additional vein running from the pelvis draining directly into this interiliac vein was observed.

Another variation in this case was the origin of the $\mathrm{CHA}$. Instead of being a branch of the coeliac trunk as usual, this artery arose from the SMA (Fig. 3). The $\mathrm{CHA}$ passed superior to the pancreatic head then coursed posterior to the main portal vein and gave 


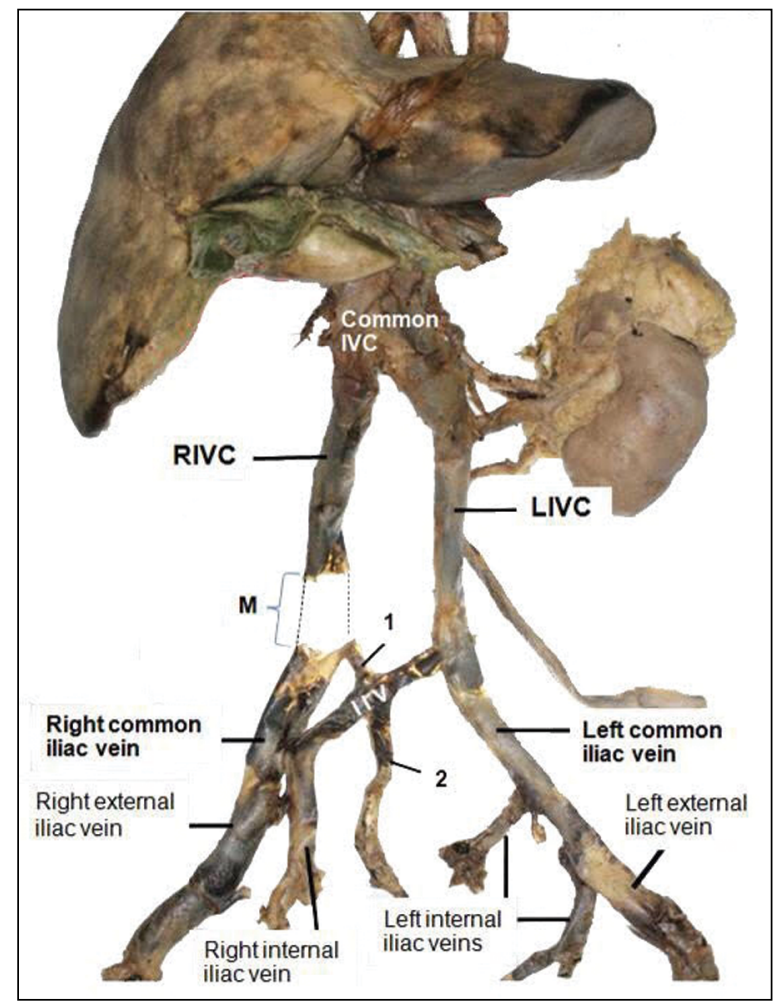

Figure 2. Liver specimen, left kidney and double inferior vena cava (IVC); M - missing part of right-sided IVC; IIV — interiliac vein; 1 - communicating vein from IIV to the right common iliac artery (RIVC); 2 - an extra pelvic vein; LIVC — left-sided inferior vena cava.

off two branches: the gastroduodenal and the proper hepatic arteries. The proper hepatic artery coursed further retroportally and divided into the right and left hepatic arteries to supply the liver (Fig. 4). The coeliac trunk in this case gave off three branches: the left gastric, the splenic and the dorsal pancreatic arteries (Figs. 1, 3). The proximal part of the dorsal pancreatic artery was hidden by the coeliac ganglion (Fig. 3). No other variation was observed.

\section{DISCUSSION}

The development of IVC has been described earlier in several articles of anomalies of the IVC $[3,7,13-15,21$, $22,25,36]$. Briefly, the infra hepatic portion of the IVC originates from three pairs of veins, namely, postcardinal, subcardinal and supracardinal veins during the fourth to eighth week of gestation. These pairs of embryonic veins undergo the process of fusion, regression and midline anastomoses to develop the retroperitoneal veins in adults. The suprarenal and renal segments of the IVC derive from the right subcardinal vein. The infrarenal IVC segment derives from the right suprarenal vein and from

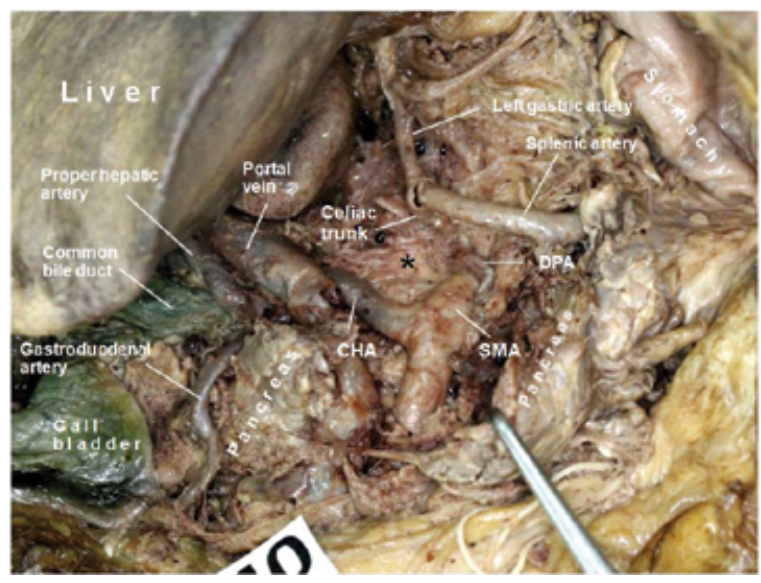

Figure 3. The origin of common hepatic artery (CHA) from the superior mesenteric artery (SMA). Note the suprapancreatic retroportal course of the CHA. The three branches of coeliac trunk: left gastric, splenic and dorsal pancreatic arteries (DPA). The proximal part of DPA (white asterisk) was hidden by part of the coeliac ganglion (black asterisk).

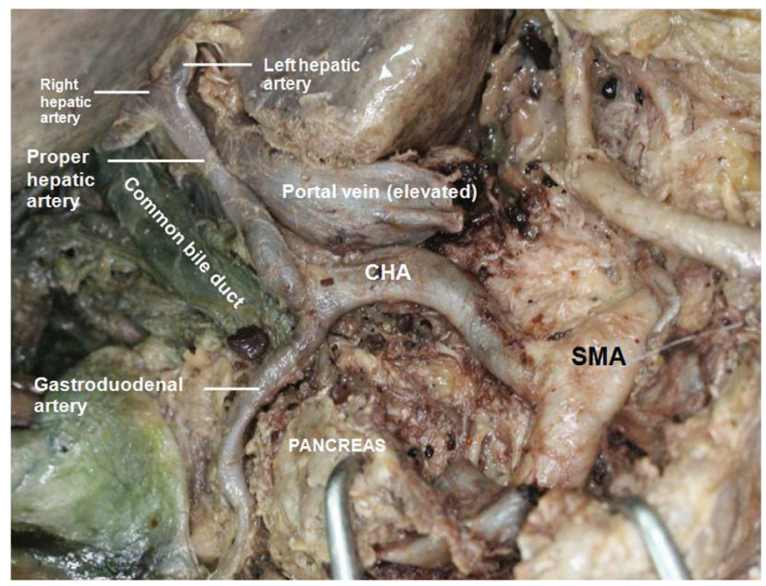

Figure 4. The common hepatic artery (CHA) divided into gastroduodenal and proper hepatic arteries. The proper hepatic artery coursed retroportally and divided into right and left hepatic arteries. The tributaries of the portal vein were removed and the portal vein was elevated to expose the CHA and proper hepatic artery; SMA superior mesenteric artery.

its anastomoses with the subcardinal vein. The iliac veins derive from the post cardinal veins [36]. Anomalies of the IVC result from the abnormal development in regression and anastomoses of these three pairs of embryonic veins. The double IVC results from persistence of both the left and right supracardinal vein. The literature revealed that usually, the left-sided IVC ends at the level of the left renal vein, crosses over the abdominal aorta to join the rightsided IVC [24]. However, there might be variations in this 
arrangement [3]. In the present case, the left-sided IVC at the level above the left renal vein crossed the abdominal aorta to join the right-sided IVC. The diameter of the left-sided IVC was larger than the right one. Associated variations of the venous structures and anomalies have been described earlier $[4,30,34]$. In the present case, the variations of the interiliac vein and the aberrant origin of the $\mathrm{CHA}$ were associated.

Pelvic venous variations of the double IVC anomalies were classified into five subtypes (subtype 2a-2e) according to the pattern of the interiliac communicating vein [18]. The variation of pelvic vein in the present case was similar to subtype $2 \mathrm{e}$ in that the interiliac vein communication was from the right internal iliac vein to the left common iliac vein (left-sided IVC). Hayashi et al. [8] proposed a new classification of variations in the iliac venous system based on the internal iliac vein into three types: internal iliac vein draining into the ipsilateral external iliac vein (type $\mathrm{L}$ ); confluence of external iliac vein and IVC (type S); and the communicating vein (type M). In the present case, the right internal iliac vein drained into the confluence of ipsilateral external iliac vein and IVC (type S) while the two left internal iliac veins drained into the ipsilateral external iliac vein (type L). More complex variations were the presence of another communicating vein from the interiliac vein to the right common iliac vein (right-sided IVC) and an extra vein from the pelvis draining directly into the middle part of the interiliac vein. These pelvic venous variations have not been reported previously $[8,18,32$, 35]. Pelvic venous variations have the potential to cause haemorrhagic complications during pelvic surgery and venous interventional radiology [8].

Co-existence of the aberrant CHA from the SMA and double IVC in this case has not been reported elsewhere. The development of the ventral aortic branches supplying the gut tube and derivatives occur during the fourth to seventh week of gestation, which is the same period of the IVC formation [26, 27]. Knowledge of variations in the branching pattern of the coeliac trunk is important for surgeries of the stomach, duodenum, pancreas and hepatobiliary system. Classification of the hepatic arterial system has been proposed firstly by Michels in 1966 [17] into ten types based on the origin of the right and left hepatic arteries and the presence of aberrant hepatic arteries. The origin of the CHA from the SMA belonged to type 9 with a prevalence of $2.5 \%$. Later, a modification of Michels' classification scheme into six types or Hiatt's classification was widely used $[9,28,37]$. The CHA from SMA was classified as type
5 with a prevalence of $1.5 \%$. Besides the origin of the $\mathrm{CHA}$, the retro portal course of CHA and its proper hepatic artery were also a rare variation. Song et al. [29] had reported 148 CHAs (from 4939 patients or 3\%) arising from the SMA showing diverse relationships with the pancreas. Among these cases, $85 \mathrm{CHAs}$ had suprapancreatic retroportal course. Awareness of such variable arterial pattern is relevant for interventions of intra-arterial management of hepatic tumour, successful liver transplantation and hepatobiliary surgery.

\section{CONCLUSIONS}

In conclusion, the asymptomatic double IVC with complex interiliac vein communication co-existed with aberrant $\mathrm{CHA}$ arising from SMA in this reported case is important because it can deceive surgeons during abdominal and pelvic operations or can be confused with pathologic conditions on abdominal imaging performed for other reasons.

\section{Acknowledgements}

The authors would like to acknowledge the following medical students: Sarun Intaralawan, Sarutya Tungjairukkarndee, Sasicha Kitphati, Sorawat Ketkaewmanee, Vitsarat Ratanasirisawad, Wisawa Wareephob and the staff in the Department of Anatomy, Faculty of Medicine, Chulalongkorn University for all their help and support.

\section{REFERENCES}

1. Arjhansiri $K$, Charoenrat $P$, Kitsukjit W. Anatomic variations of the hepatic arteries in 200 patients done by angiography. J Med Assoc Thai. 2006; 89 Suppl 3: S161-S168, indexed in Pubmed: 17718283.

2. Babaian RJ, Johnson DE. Major venous anomalies complicating retroperitoneal surgery. South Med J. 1979; 72(10): 1254-1258, indexed in Pubmed: 482980.

3. Bass JE, Redwine MD, Kramer LA, et al. Spectrum of congenital anomalies of the inferior vena cava: cross-sectional imaging findings. Radiographics. 2000; 20(3): 639-652, doi: 10.1148/radiographics.20.3.g00ma09639, indexed in Pubmed: 10835118.

4. Chaijaroonkhanarak W, Pannangrong W, Welbat JU, et al. Double inferior vena cava with three shunts: a rare anomaly with important implications for surgeons. Folia Morphol. 2017; 76(2): 307-311, doi: 10.5603/FM.a2016.0076, indexed in Pubmed: 28026845.

5. Chen $H$, Yano R, Emura $S$, et al. Anatomic variation of the celiac trunk with special reference to hepatic artery patterns. Ann Anat. 2009; 191(4): 399-407, doi: 10.1016/j. aanat.2009.05.002, indexed in Pubmed: 19540742.

6. Chen $\mathrm{H}$, Emura $\mathrm{S}$, Nagasaki $\mathrm{S}$, et al. Double inferior vena cava with interiliac vein: a case report and literature review. Okajimas Folia Anat Jpn. 2012; 88(4): 147-151, indexed in Pubmed: 22645906. 
7. Friedland GW, deVries PA, Nino-Murcia M, et al. Congenital anomalies of the inferior vena cava: embryogenesis and MR features. Urol Radiol. 1992; 13(4): 237-248, indexed in Pubmed: 1598750.

8. Hayashi S, Naito M, Hirai S, et al. Proposal for a new classification of variations in the iliac venous system based on internal iliac veins: a case series and a review of double and left inferior vena cava. Anat Sci Int. 2013; 88(4): 183-188, doi: 10.1007/ s12565-013-0182-1, indexed in Pubmed: 23709295.

9. Hiatt JR, Gabbay J, Busuttil RW. Surgical anatomy of the hepatic arteries in 1000 cases. Ann Surg. 1994; 220(1): 50-52, indexed in Pubmed: 8024358.

10. Ito $T$, Ikeda $Y$. A case of double inferior vena cava with renal, ovarian and iliac vein variation. Anat Sci Int. 2018; 93(1): 139-143, doi: 10.1007/s12565-017-0397-7, indexed in Pubmed: 28283881.

11. Lataifeh $A R$, Anderson P. Duplication of inferior vena cava: a rare but clinically significant anatomical variation. $\mathrm{NZ}$ Med J. 2014; 127(1405): 84-86, indexed in Pubmed: 25399047.

12. Lucas MF. A case of double inferior vena cava. J Anat. 1916; 51(Pt 1): 69-70, indexed in Pubmed: 17103805.

13. Malaki $M$, Willis $A P$, Jones RG. Congenital anomalies of the inferior vena cava. Clin Radiol. 2012; 67(2): 165-171, doi: 10.1016/j.crad.2011.08.006, indexed in Pubmed: 22070941.

14. Mathews R, Smith PA, Fishman EK, et al. Anomalies of the inferior vena cava and renal veins: embryologic and surgical considerations. Urology. 1999; 53(5): 873-880, indexed in Pubmed: 10223477.

15. Mayo J, Gray R, St Louis E, et al. Anomalies of the inferior vena cava. AJR Am J Roentgenol. 1983; 140(2): 339-345 doi: 10.2214/ajr.140.2.339, indexed in Pubmed: 6336872.

16. McClure $C$, Butler $E$. The development of the vena cava inferior in man. Am J Anat. 1925; 35(3): 331-383, doi: 10.1002/ aja. 1000350302 .

17. Michels NA. Newer anatomy of the liver and its variant blood supply and collateral circulation. Am J Surg. 1966; 112(3): 337-347, indexed in Pubmed: 5917302.

18. Morita S, Higuchi M, Saito N, et al. Pelvic venous variations in patients with congenital inferior vena cava anomalies: classification with computed tomography. Acta Radiol. 2007; 48(9): 974-979, doi: 10.1080/02841850701499409, indexed in Pubmed: 17957511.

19. Mu GC, Huang Y, Liu ZM, et al. Clinical research in individual information of celiac artery $C T$ imaging and gastric cancer surgery. Clin TransI Oncol. 2013; 15(10): 774-779, doi: 10.1007/ s12094-013-1002-8, indexed in Pubmed: 23359186.

20. Musiksilp S, Udomsawaengsup S, Panichabhongse V. Anatomical variations of extrahepatic artery in Thai people, 29th annual congress of the Royal College of Surgeons of Thailand, 31 July-2 August 2004. Thai J Surg. 2004; 25: 93.

21. Nagashima T, Lee J, Andoh K, et al. Right double inferior vena cava: Report of 5 cases and literature review. J Comput Assist Tomogr. 2006; 30(4): 642-645, indexed in Pubmed: 16845296.

22. Natsis K, Apostolidis S, Noussios G, et al. Duplication of the inferior vena cava: anatomy, embryology and classification proposal. Anat Sci Int. 2010; 85(1): 56-60, doi: 10.1007/ s12565-009-0036-z, indexed in Pubmed: 19330283.

23. Prabhasavat $K$, Homgade $C$. Variation of hepatic artery by 3-D reconstruction MDCT scan of liver in Siriraj Hospital.
J Med Assoc Thai. 2008; 91(11): 1748-1753, indexed in Pubmed: 19127799.

24. Raza Ss, Farid S, Reddy Ms, et al. Duplication of the inferior vena cava. J Surg Case Rep. 2011; 2011(9): 10, doi: 10.1093/jscr/2011.9.10, indexed in Pubmed: 24950511.

25. Sandercoe GD, Brooke-Cowden GL. Developmental anomaly of the inferior vena cava. ANZ J Surg. 2003; 73(5): 356-360, indexed in Pubmed: 12752300.

26. Schoenwolf GC, Bleyl SB, Brauer PR, Francis-West PH. Dorsal aorta develops ventral, lateral, and posterolateral branches. In:Larsen's Human Embryology, 4th Ed. Livingstone, Philadelphia 2009: 408-410.

27. Schoenwolf GC, Bleyl SB, Brauer PR, Francis-West PH. Primitive embryonic venous system is divided into vitelline, umbilical, and cardinal systems. In:Larsen's Human Embryology.4th Ed. Livingstone, Philadelphia 2009: 419-424.

28. Sebben GA, Rocha SL, Sebben MA, et al. Variations of hepatic artery: anatomical study on cadavers. Rev Col Bras Cir. 2012; 40(3): 221-226, indexed in Pubmed: 23912370.

29. Song SY, Chung JW, Yin YHu, et al. Celiac axis and common hepatic artery variations in 5002 patients: systematic analysis with spiral CT and DSA. Radiology. 2010; 255(1): 278-288, doi: 10.1148/radiol.09090389, indexed in Pubmed: 20308464.

30. Spentzouris G, Zandian A, Cesmebasi A, et al. The clinical anatomy of the inferior vena cava: a review of common congenital anomalies and considerations for clinicians. Clin Anat. 2014; 27(8): 1234-1243, doi: 10.1002/ca.22445, indexed in Pubmed: 25042045.

31. Sreesai M, Chittmittrapap S. A study of the surgical anatomy of hepatic arteries. Chula Med J. 1986; 30: 313-324.

32. Tankruad S, Suwannakhan A, Suriyonplengsaeng C, et al. Duplication of the inferior vena cava from a division of the left external iliac vein. Anat Sci Int. 2017; 92(1): 147-150, doi: 10.1007/s12565-016-0356-8, indexed in Pubmed: 27401745.

33. Thangarajah A, Parthasarathy R. Celiac Axis, Common Hepatic and Hepatic Artery Variants as Evidenced on MDCT Angiography in South Indian Population. J Clin Diagn Res. 2016; 10(1): TC01-TC05, doi: 10.7860/JCDR/2016/17045.7105, indexed in Pubmed: 26894140.

34. Tore HG, Tatar I, Celik HH, et al. Two cases of inferior vena cava duplication with their $\mathrm{CT}$ findings and a review of the literature. Folia Morphol. 2005; 64(1): 55-58, indexed in Pubmed: 15832272.

35. Vidal V, Monnet $O$, Jacquier $A$, et al. Accessory iliac vein: surgical implications. J Spinal Disord Tech. 2010; 23(6): 398-403, doi: 10.1097/BSD.0b013e3181b26c88, indexed in Pubmed: 20124922.

36. Yang $\mathrm{C}$, Trad $\mathrm{H}$, Mendonça $\mathrm{S}$, et al. Congenital inferior vena cava anomalies: a review of findings at multidetector computed tomography and magnetic resonance imaging. Radiol Bras. 2013; 46(4): 227-233, doi: 10.1590/s010039842013000400009

37. Zagyapan R, Kürkçüoğlu $A$, Bayraktar $A$, et al. Anatomic variations of the celiac trunk and hepatic arterial system with digital subtraction angiography. Turk J Gastroenterol. 2014; 25 (Suppl 1): 104-109, doi: 10.5152/tjg.2014.5406, indexed in Pubmed: 25910286. 